\title{
DAS TERRAS DE PRETO À SALA DE AULA: MODALIDADE EDUCACIONAL QUILOMBOLA, UM ENSINO PARA TODOS
}

\author{
Eleno Marques de Araújo ${ }^{l}$ \\ Samuel Pedro Gonzaga ${ }^{2}$ \\ José Humberto Rodrigues dos Anjos ${ }^{3}$
}

\section{INTRODUÇÃO}

Desde que foram homologadas pelo Ministério da Educação pela Resolução 8 de 20 de novembro de 2012, as Diretrizes Curriculares Nacionais para a Educação Escolar Quilombola e a Conferência Nacional de Educação (CONAE, 2010) passou a exigir que sejam abarcadas, articuladas, implementadas e respeitadas suas especificidades pelos órgãos União, Estados, Distrito Federal e Municípios, segundo o art. $2^{\circ}$.

Por isso, os órgãos responsáveis passaram a implementar e gerir as atividades, os processos pedagógicos, aliados às comunidades tradicionais, local próprio onde ocorre o desenvolvimento de vivências de mundo na unicidade, não na uniformidade, uma vez que são delas que nascem todas as formas correlatas deste processo da ensinagem que, usando o mesmo viés dos povos indígenas se intitulam "povos com educação diferenciada". Como resultado de lutas e conquistas insere-se aqui uma espécie de 'abertura' para o estudo obrigatório da cultura e história dos povos africanos, por todos os alunos brasileiros. Segundo Gomes (2012, p. 100) é oportuna “a demanda curricular de introdução obrigatória do ensino de História da África e das culturas afro-brasileiras nas escolas da educação básica”. Entretanto, Gomes reconhece a complexidade que o assunto demanda e acrescenta:

ela exige mudança de práticas e descolonização dos currículos da educação básica e superior em relação à África e aos afro-brasileiros. Mudanças de representação e de práticas. Exige questionamento dos lugares de poder. Indaga a relação entre direitos e

\footnotetext{
${ }^{1}$ Doutorado em Ciências da Religião pela Pontifícia Universidade Católica de Goiás, Brasil (2012) Adjunto do Centro Universitário de Mineiros, Brasil. Pós doutorando pela UNIUBE - Universidade de Uberaba, no Programa de PósGraduação em Educação, sobre a orientação da profa. Dra. Vania Maria de Oliveira Vieira. profelenoaraujo@outlook.com

${ }^{2}$ Licenciado em Pedagogia pela FAI - Itapuranga (Goiás). Especializando em Educação Especial pela FAFIRE-PE. samuelpedrogonzaga@gamail.com

${ }^{3}$ Mestre em Estudos da Linguagem pela Universidade Federal de Goiás. Doutorando em Educação pela Universidade de Uberaba - UNIUBE. Atualmente é docente adjunto do Centro Universitário de Mineiros, onde ministra as disciplinas de Leitura e produção de texto e Educação étnico-racial. E-mail: josehumberto@ fimes.edu.br
} 
privilégios arraigada em nossa cultura política e educacional, em nossas escolas (GOMES, 2012, p. 100).

A educação, de forma geral, é um elemento dos componentes culturais. No primeiro momento, ela é concretizada pela família e/ou cuidadores ou pela comunidade em que estão inseridas as pessoas a serem instruídas por meio da educação não formal. No segundo momento, ela passa a ser de responsabilidade também dos órgãos já citados, não eximindo a parceria e a incumbência da família. Acrescenta-se que a educação nos âmbitos informal ou formal também é um fato social e consequentemente cultural ${ }^{4}$.

Neste sentido, tratando a educação como cultura, pode-se evocar o pensamento de Chizzotti (1994, p. 93), ao afirmar que o objeto da ciência social consiste em:

buscar o significado que as pessoas dão ao seu mundo e as suas práticas, ou seja, a toda a soma total de objetos e dos acontecimentos do mundo cultural e social criados pelo pensamento comum dos homens, vivendo numerosas interações sociais. Cabe aos pesquisadores identificar e descrever as práticas e os significados sociais [...], de compreender como elas se dão no contexto dos sujeitos que as pratica.

Para tanto, observa-se que a visão de mundo depende da imersão do sujeito em um contexto histórico que reconhece as causas sociais desse chão epistemológico, locos que permite a primeira identificação do sujeito que se percebe distinto da realidade que o cerca. É nesse sentido que a educação quilombola deve ser situada, uma vez que, os sujeitos a ela inerentes têm um passado, um presente e um futuro a ser construído de forma autóctone e absolutamente distinta de sobreposições do passado. É também em contexto como esse que Freire (1986) quis afirmar a necessidade da educação de jovens e adultos a partir da realidade em que vivem, como um local próprio de autonomia da consciência dos educandos como sujeitos do processo de apreender. A primeira condição de autonomia do sujeito é dar conta de sua existência e saber perceber a realidade que o envolve, separando-se criticamente dela. Assim, afirma Freire:

se antes a alfabetização de adultos era tratada e realizada de forma autoritária, centrada na compreensão mágica da palavra, palavra doada pelo educador aos analfabetos; se antes os textos geralmente oferecidos como leitura aos alunos escondiam muito mais do que desvelavam a realidade, agora, pelo contrário, a alfabetização como ato de conhecimento, como ato criador e como ato político é um esforço de leitura do mundo e da palavra (Freire, 1986, p. 35).

\footnotetext{
${ }^{4}$ A professora Jerusa Vieira Gomes aborda de forma muito profícua a questão da educação formal e informal em seu artigo intitulado "Relações Família e Escola - Continuidade/Descontinuidade no Processo Educativo", disponível na internet.
} 
Nesse contexto, a educação como fator cultural e social está inclusa nas pautas das grandes discussões globais proferidas pelas nações e órgãos mundiais, sobretudo, em foros sociais. Porém, há falta de investimentos por parte dos governantes em áreas fundamentais que sustentam e guiam uma sociedade com equidade e, a educação, sendo o eixo de qualquer emancipação humana carece desse investimento, bem como de políticas afirmativas que alavanquem os indivíduos para uma realidade autônoma. No entanto, não é perceptível a mesma discussão nas pautas dos grandes mercados capitalistas que não dispensam atenção e investimentos necessários para que seja viabilizada uma educação inclusiva.

Contudo, afirma-se que a educação para além das "terras de preto" é uma vitória que está sendo construída com muita luta e busca da efetivação dos direitos dos povos advindos forçadamente da África, em tempos de mercantilismo escravo, e que ainda hoje continuam sofrendo as consequências de serem negros ou descendentes deles. Oxalá essa vitória leve à existência e o desenvolvimento concreto de possibilidades de reparação desse prejuízo de direito educacional que lhes foram retirados, especialmente, por meio de novas políticas afirmativas. Essa modalidade de ensino só será possível mediante uma construção que permita a unicidade dos pensamentos multiculturais, dialética contra-hegemônica aos grupos que formam o bloco: monocultural capitalista que tem atuado em direção contrária a esses ideais.

De outro lado, continuará o processo de resistência de setores que pensam o contrário da autonomia humana, e, certamente, tentará processos de desconstrução das garantias sociais já alcançadas. Neste sentido, Freitas reconhece que a educação segue desafiadora, e somente por meio de ações concretas poderá lograr resultados satisfatórios. Dessa forma, assegura que:

para que as atividades propostas se viabilizem na prática, é necessário ter uma postura e sensibilidade por parte dos educadores que nelas trabalharão para, num primeiro momento, captar os anseios e os conhecimentos que as crianças, jovens, adultos e idosos, de grupos sociais diferentes e pertencentes a contextos sociais e culturais diferenciados, transmitem através de suas histórias de vida. Só assim será possível construir um diálogo a partir dos conhecimentos oferecidos por essa população e da bagagem acumulada pelos educadores (FREITAS, 1982, p. 210).

Desse modo, o bloco monocultural capitalista tenta dissimular que esses diálogos ocorram com maestria, pois deles nascem novos atores concretos que visibilizarão a nova proposta discutida por Boaventura de Souza Santos, quando identifica os excluídos como invisíveis e ausentes da sociedade, ofertando-lhes possibilidades de pensar e construir novas fontes de pesquisas e conhecimentos, formando a igualdade cultural que transversalizam saberes do sul ao norte e viceversa. 
Cabe aqui a valiosa contribuição do professor Gil ao fazer uma análise de uma comunidade de investigação ou pesquisa. Nesse caso, ela pode assumir múltiplas faces, sem que necessariamente estejam ligadas a uma localidade específica:

[...] focaliza uma comunidade, que não é necessariamente geográfica, pode ser uma comunidade de trabalho, de estudo, de lazer, ou voltada para qualquer outra atividade humana [...] o pesquisador realiza a maior parte do trabalho pessoalmente, é enfatizada a importância de o pesquisador ter tido ele mesmo uma experiência direta com a situação de estudo. [...] pois somente com essa imersão na realidade, é que se podem entender as regras, os costumes e as convenções que regem o grupo estudado (Gil, 2002, p. 53).

A que ressaltar, no entanto, que Gil insere o pesquisador não só no processo de pesquisa, mas como experiência vivencial in loco, isto é, para ter autoridade em falar dos temas tratados ele deve ter vivenciado com a comunidade pesquisada. No caso da educação quilombola, não restam dúvidas de que Samuel é descendente natural dos afrodiásporas ${ }^{5}$. Mas, não só, porque Eleno, embora não apresente cor negra, também é brasileiro, e como tal recebeu muito dos povos advindos daquele continente.

\section{DAS TERRAS DE PRETO: UM ENSINO SEM COR}

Os povos africanos transportados para o Brasil, com a finalidade de servir como mão-deobra escrava, sobretudo, nas fazendas de café e de cana-de-açúcar, quase sempre foram duramente explorados e mal tratados em todos os sentidos. Como alternativa a essa realidade de dominação, maus tratos e exploração, a possibilidade mais imediata era a fuga das senzalas, buscando assim, lugares de difícil acesso o que impedia a recapturação. Neste sentido, os fugitivos foram aglomerando e criando novas comunidades que, posteriormente, ficaram conhecidas como quilombos. Conforme a definição de Nascimento (2002, p. 264):

Os quilombos resultaram dessa exigência vital dos africanos escravizados, no esforço de resgatar sua liberdade e dignidade através da fuga ao cativeiro e da organização de uma sociedade livre [...] o quilombismo se estruturava em formas associativistas que tanto podiam estar localizadas no seio de florestas de difícil acesso que facilitava sua defesa e sua organização econômico-social própria, como também assumiram modelos de organizações permitidas ou toleradas, frequentemente com ostensivas

\footnotetext{
${ }^{5} \mathrm{O}$ termo diáspora é empregado desde a antiguidade conotando a última grande dispersão do povo judeu no ano 150 da Era Cristã. Aqui ele assume o mesmo sentido, uma vez que identifica a dispersão dos povos africanos através da escravatura negra.
} 
finalidades religiosas (católicas), recreativas, beneficentes, esportivas, culturais ou de auxilio mútuo.

A partir do século $\mathrm{XV}$, os quilombos tornaram-se lugares de refúgio para todos aqueles rejeitados e massacrados pela sociedade vigente da época e, nesse caso, nomeado aqui de afrodiásporas, também os índios e brancos, todos oprimidos pelos pensares da colonialidade. No entanto, Freitas coloca que como movimento de resistência:

o 'Quilombo dos Palmares' foi a manifestação mais eloquente do discurso antiescravista dos negros brasileiros nos quase três séculos da escravidão, representando um marco na resistência negra. A resolução tomada na Serra da Barriga 'de morrer antes de aceitar a escravidão', demonstra a essência da mensagem que os negros de Palmares deixaram. Conclui o autor, retomando a reflexão hegeliana: ' $O$ Amo não é Amo senão pelo fato de que possui um Escravo que o reconhece como tal' (FREITAS, 1982, p. 210).

Segundo Chiavenato (1987), foram extirpados cerca de 100 milhões de Negros da África e desses números chegaram para as Terras Tupiniquins mais de 3,5 milhões de negros africanos. Ainda no tocante ao continente africano, pode-se afirmar que este sofreu um grande impacto por ter seus povos sequestrados, famílias dilaceradas, sociedades corrompidas, muitos adoeciam e morriam antes de chegar ao destino final, quando eram vendidos e iam para as senzalas. Mas, com toda essa indignação um pequeno grupo conseguiu retornar a terra mãe: África. "Os malês ou os negros islâmicos", que ao chegarem em Benin ficaram conhecidos como "os retornáveis".

É importante ressaltar que essas lutas e avanços preenchem antigas lacunas que formaram marcas e feridas nesses povos. Porém, um dos seus maiores legados dos oprimidos foi sempre a coragem e a capacidade de resistência. A união dos negros africanos caracterizou com sua maior força, visto que em momento algum, deixaram-se abater, mesmo nos períodos tensos que viveram ou diante dos castigos a que foram submetidos.

Todavia, os negros escravizados sabiam que poderiam transpor barreiras e superar limites. Essa realidade é expressa por meio dos movimentos como: os Retornáveis, os Quilombos, e a Modalidade Educacional Quilombola, entre outros, que resultou no emponderamento do setor de dominação aniquilando e silenciando o movimento de resistência intimidando e inviabilizando processos sócio-histórico-cultural de libertação. Nascimento (1980, p. 6) aponta que

os quilombolas dos séculos XV, XVI, XVII, XVIII e XIX nos legaram um patrimônio de prática quilombista. Cumpre aos negros atuais manter e ampliar a cultura afrobrasileira de resistência ao genocídio e de afirmação da sua verdade. Um método de análise, compreensão e definição de uma experiência concreta, o quilombismo 
expressa a ciência do sangue escravo, do suor que este derramou enquanto pés e mãos edificadores da economia deste país. Um futuro de melhor qualidade para a população afro-brasileira só poderá ocorrer pelo esforço enérgico de organização e mobilização coletiva, tanto da população negra como das suas inteligências e capacidades escolarizadas, para a enorme batalha com a criação teórico-científica.

Ainda nesse viés, Brasil (2013), O’Dwyer (2002), Munanga (1996), Nascimento (1980), Santana (2005), afirmam que as nomenclaturas "Terra de Pretos", "Comunidades Rurais Tradicionais", "Remanescentes de Quilombo", “Quilombismo”, “Quilombagem”, “Mocambos” e/ ou "Calhambolas", são termos significativos para identificar comunidades tradicionais de acordo com o decreto Art. $3^{0}$ e a Convenção 169 da OIT. Também é importante, nesse contexto, evocar a carta magna do Brasil (CF de 1988), no que tange a propriedade coletiva da terra e das questões culturais, em relação aos quilombolas. Assim sendo, o artigo 68, determina:

Aos Remanescentes das Comunidades dos Quilombos que estejam ocupando suas terras é reconhecida à propriedade definitiva, devendo o Estado, emitir-lhes os respectivos títulos. Garantindo também os direitos culturais, definindo como responsabilidade do Estado a proteção das manifestações das culturas populares, indígenas e afrodescendentes.

Nesse contexto, notar-se-á a presença da forma de afirmação racial, sociopolítica, pois em novas terras os protestos contra o regime opressor se fortaleceram entre outras questões. Portanto, as especificidades de cada comunidade afrodiáspora dependerão da região em que estão localizadas. Todas são diferentes em suas vivências de mundo de acordo com o local onde habitam, bem como, procuram identificar ou representar de forma simbólica o território em que vivem com o seu país de origem na África. Daí ser possível a percepção e identificação de elementos culturais próprios de uma comunidade e a completa ausência deles em outras, conforme a regionalização em destaque.

Contudo, todas essas dialogicidades estão sempre em pauta nos encontros de educação promovidos pelos órgãos físcais CONAE, CONAQ, CNE, etc., pois ainda há resquícios de uma didática tradicional, instrumental, segmentada e fragmentada por parte de alguns professores, como destaca Candau (2013). Nessa linha de pensamento também situa Freire (1987), ao assegurar que muitos professores transformam a sala de aula em "agência bancária" e os alunos em "conta poupança". Além de Candau e Freire, Moser (2013) reflete sobre essa visão de educação fragmentada e escreve em palavras similares que o pensar vazio é a subalternização de um modelo de educação excludente e cristalizado. Entretanto, para o professor Demo (2006), os professores que só reproduzem as aulas, copiando o pensamento de outros, nunca foram e jamais serão educadores. 
Nesse viés, segundo Brasil (2013), o artigo. $1^{\text {o }}$ desta Resolução determina que nas unidades escolares quilombolas urbanas e rurais reproduzam a Educação Infantil, Ensino Fundamental, Ensino Médio, Educação do Campo, Educação Especial, Educação Profissional Técnica de Nível Médio, Educação de Jovens e Adultos, inclusive a Educação a Distância; pois entre a Resolução No 8 de 2012 e a LDB não há indissociabilidade da formação escolar brasileira, todavia, compõem a educação básica nacional conforme o Parecer CNE/CEB no 7/2010.

Munanga afirma que a educação no contexto das novas exigências continuará como desafio a ser superado pelos componentes da ação educadora. Nesse sentido,

para que a escola consiga avançar na relação entre saberes escolares/realidade social/diversidade étnico-cultural é preciso que os educadores(as) compreendam que o processo educacional também é formado por dimensões como a ética, as diferentes identidades, a diversidade, a cultura, as relações raciais, entre outras. E trabalhar com essas dimensões não significa transforma-la em conteúdos escolares ou temas transversais, mas ter a sensibilidade para perceber como esses processos constituintes da nossa formação humana se manifestam na nossa vida no próprio cotidiano escolar. Dessa maneira, poderemos construir coletivamente novas formas de convivência e de respeito entre professores, alunos e comunidade (MUNANGA, 2005, p.147).

Por isso, conduzidas pelas instituições de ensino, os saberes quilombolas constroem uma afroperspectiva nos educandos multifacetados com as pluralidades culturais somadas à formação recebida nas salas de aula. Na visão de Santos (2009), será por meio das "ecologias de saberes" que fará a negação das monoculturas globalizadas, perfazendo segundo Gomes (2012), a construção da transversalidade emancipatória africana e afro-brasileira, tornando suas culturas credíveis.

Nos Parâmetros Curriculares Nacionais (PCN - Temas Transversais, 1997, p. 27), a temática é assegurada da seguinte forma:

para viver democraticamente em uma sociedade plural é preciso respeitar os diferentes grupos e culturas que a constituem. A sociedade brasileira é formada não só por diferentes etnias, como por imigrantes de diferentes países. Além disso, as migrações colocam em contato grupos diferenciados. Sabe-se que as regiões brasileiras têm características culturais bastante diversas e a convivência entre grupos diferenciados nos planos social e cultural muitas vezes é marcada pelo preconceito e pela discriminação. O grande desafio da escola é investir na superação da discriminação e dar a conhecer a riqueza representada pela diversidade etnocultural que compõe o patrimônio sociocultural brasileiro, valorizando a trajetória particular dos grupos que compõem a sociedade. Nesse sentido, a escola deve ser local de diálogo, de aprender a 
conviver, vivenciando a própria cultura e respeitando as diferentes formas de expressão cultural.

O princípio norteador dos PCN admite a grande variedade cultural presente no âmbito do território brasileiro. Os PCN advertem ainda que há a necessidade de valorizar a multicuturalidade, uma vez que a sociedade brasileira é composta por uma nação que teve origem em diferentes povos que migraram para o Brasil. Entretanto, conforme Jaccoud (2008, p. 137), é perceptível que:

a presença do racismo, do preconceito e da discriminação como práticas sociais, aliadas à existência do racismo institucional, representa um obstáculo à redução daquelas desigualdades, obstáculo este que só poderá ser vencido com mobilização de esforços de cunho específico. Assim, a implementação de políticas públicas específicas, capazes de dar respostas mais eficientes frente ao grave quadro de desigualdades raciais existente em nossa sociedade, apresenta-se como exigência incontornável na construção de um país com maior justiça social.

Para alcançar a justiça social "implica a construção de práticas pedagógicas de combate à discriminação racial, um rompimento com a 'naturalização' das diferenças étnico/raciais, [...] Uma alternativa para a construção de práticas pedagógicas que se posicionem contra a discriminação racial" (GOMES, 2003, p. 77).

A atmosfera que circunda a produção de vida dos quilombolas surge com a "terra", "território" e "territorialidade". Essas acepções constituem a forma africana mantenedora de enraizamento dos laços de pertencimentos e fazem brotar as subsistências que são as formas de sobrevivência de todos os seres ligados pelos pertencimentos seja pelos multiculturais ou pelos que formam toda uma cadeia alimentar.

O termo 'terra de uso comum' de acordo com a territorialidade ela teria diferentes definições locais [...] tais como Terras de Santo, Terras de Índios, Terras de Parentes, Terras de Irmandade, Terras de Herança e, finalmente, Terras de Preto, domínios doados, entregues ou adquiridos, com ou sem formalização jurídica, por famílias de escravos (ALMEIDA apud ARRUTI, 2008, p. 15).

Para Barros (2011), Beniste (2014), Buber (2011), “Água", "Terra”, "Fogo" e "Ar" formam pertencimentos que favorecem a relação cognitiva dos negros e negras que trouxeram na mente e no corpo uma pedagogia milenar fundamental que é perpetuada por meio da Ancestralidade, Oralidade e Natureza. Também se entende que para Kochhann e Moraes (2014), é a aprendizagem significativa que interage com os saberes existentes da estrutura cognitiva da pessoa, nesse caso, educandos quilombolas. 
Conforme o discurso, como prática afropedagógica, entende-se que há uma relação de dois sujeitos incluídos necessariamente: “O Eu se torna Eu em virtude do Tu. Isto não significa que devo a ele o meu lugar. O Eu lhe devo a minha relação a ele [...]”. (BUBER, 2001, p. 32). Nesse contexto, "a força do aprendizado que se fundamenta na perspectiva empírica, baseada na oralidade, constitui-se numa pedagogia iniciática pautada na observação contínua [...]” (BARROS, 2011, p. 46). Nesse viés, acrescenta Beniste (2014, p. 79) que o meu Eu é constituído a partir da integração “com reino mineral, vegetal, e animal” como relação intrínseca e necessária de uma harmonia contínua.

Portanto, os valores civilizatórios afro-brasileiros transpassam os olhares culturais, corporeidade, causos (oralidade), religiosidade, entre outros. Existem muitas produções como, do trabalho, da vida política, da construção econômica, afinal, todos são seres que compõem este universo e, como toda sociedade, há a produção econômica para manter as comunidades.

Todavia, sabe-se que o enfrentamento dessa modalidade educacional será longo, pois todos estão presentes em uma sociedade etnocêntrica que não estabelece diálogos que constituam epistemologias para além do norte e sul, a uma nova leitura, da multiculturalidade. Como ação afirmativa, entende-se que "apenas esse investimento no conhecimento de si próprio e no saber alternativo tomando em conta as perspectivas africanas" (KI-ZERBO, 2007, p. 1).

Por conseguinte, demandará a "Ecologia dos Saberes", uma abordagem para além do Séc. XXI que modifica os pensamentos lineares sobre as questões que sobrevoam a educação negra como: currículos, didáticas, práticas pedagógicas, perfil dos educadores entre outras, afinal, está-se construindo uma educação que vem na contramão de mais de 500 anos de negação e silenciamento, para um modelo em uma afroperspectiva, a Educação Quilombola.

\section{CONCLUSÃO}

Essa bibliografia não tem presunção de findar perspectivas e visões de mundo acerca das africanidades brasileiras que por meio das lutas dos movimentos dos Negros, Luta antirracistas, Movimento Zumbi dos Palmares entre outros, fizeram nascer a Modalidade Educacional Quilombola. Porém, no Brasil ainda é usado o "mito da democracia" para invisibilizar as problemáticas sociais que envolvem a negritude que tange as boas práticas que corroboram com a eliminação da pedagogia hegemônica.

Por isso, segundo Brasil (2013), (2004), a xenofobia, preconceito racial, racismo, sexismo e todas as formas correlatas de agressões, desvantagens, marginalizações, injustiça econômica e discriminatória entre outras, deverão ser combatidas nas escolas em salas de aula, ofertando estudos 
dirigidos com base em ações afirmativas que visam correções e práticas de injustiça cognitiva que sofrem todos os grupos étnicos brasileiros, independente de sexo, idade e fenótipo.

Para tanto, segundo a Unesco (2010), os centros de ensino ainda são locais de formação humana e discussões acerca das causas que venham modificar os negativos cenários nos quais se encontra a sociedade vigente no Brasil e no mundo, ofertando um lugar com equidade, alteridade livre de práticas escravistas. Para Romão (2000), transpassar uma prática educativa e pedagógica. Neste contexto "[...] Amílcar Cabral chamava de "reafricanização das mentalidades", e isto implica na transformação radical do sistema educacional herdado do colonizador, o que não pode ser feito, porém, de maneira mecânica (FREIRE, 1978, p. 16). Nesse viés, “O conhecimento africano é imenso, variado. Concerne a todos os aspectos da vida. O 'sábio' não é jamais um 'especialista'. É um generalista" (BÂ, 1972, p. 1).

Por isso, a educação quilombola cria poderes simbólicos nos processos da ensinagem ofertando uma nova educação, linguagem, didática e metodologia com base nos conhecimentos universais entre os continentes nas relações apontadas por Boaventura de Sousa Santos (2009) “ecologia dos saberes”, negando a existência e supremacia da monocultura do Norte. 


\section{REFERÊNCIAS}

ARAÚJO, Márcia; SILVA, Geraldo. Da interdição escolar ás ações educacionais de sucesso: escolas dos Movimentos Negros e Escolas Profissionais. In: ROMÃO, Jeruse. (Org.). História da Educação do Negro e outras Histórias. Brasília: MEC, 2005.

ARRUTI. José Mauricio. Quilombos. In: Raça: Perspectivas Antropológicas. (Org. Osmundo Pinho). ABA / Ed. Unicamp / EDUFBA, 2008.

BÂ. A. H. Aspects de la Civilization Africaine, Paris, ed. Présence Africaine, 1972 e publicado em português na revista THOT n. 64, 1997). Disponível em: 〈www.casadasafricas.org.br >. Acessado em <15/04/16 às 13:40>.

BARROS, J.F.P. A floresta sagrada de Ossaim: o segredo das folhas, Rio de Janeiro: Pallas, 2011.

BRASIL. Diretrizes Curriculares Nacionais Gerais para a Educação Básica. Brasília: MEC/SECADI, novembro, 2013.

. Diretrizes Curriculares Nacionais para a Educação Escolar Quilombola na Educação Básica. Brasília: MEC/SECADI, novembro, 2013.

Diretrizes curriculares nacionais para a educação das relações étnico-raciais e para o ensino de História e Cultura Afro-brasileira e Africana. Brasília: MEC/SECADI, junho, 2004.

Parâmetros curriculares nacionais: apresentação dos temas transversais, ética / Secretaria de Educação Fundamental. Brasília: MEC/SEF, 1997.

BENISTE. J. Òrun-Áiyé: o encontro de dois mundos: o sistema de relacionamento nagô-yorubá entre o céu e a terra, 11. ed. Rio de Janeiro: Bertrand Brasil, 2014.

BUBER, M. Eu e Tu. São Paulo: Centauro, 2001.

CANDAU, V. M. (Org.). Rumo a uma nova didática. 23. ed. Petrópolis: Vozes, 2013.

CHIAVENATO, J. J. O Negro no Brasil. São Paulo: Brasiliense, 1980.

CHIZZOTTI, Antônio. O cotidiano e as pesquisas em educação. In: FAZENDA, Ivani (Org.). Novos enfoques da pesquisa educacional. 2. ed. São Paulo: Cortez, 1994.

DEMO, P. Pesquisa: princípio cientifico e educativo. São Paulo: Cortez, 2011.

FONSECA, M. V. A Educação dos Negros: Uma Face do Processo de Abolição no Brasil. Bragança Paulista: EDUSF.

FREIRE. P. Pedagogia da Autonomia: Saberes necessários à prática educativa, 44. ed. Rio de Janeiro: Paz e Terra, 2013.

1978.

Cartas à Guiné-Bissau: registros de uma experiência em processo. 2. ed., Rio de Janeiro, Paz e Terra,

GIL, A. C. Como elaborar projetos de pesquisa? 4. ed. São Paulo: Atlas, 2002.

GOMES, Nilma Lino. Educação e Relações Raciais: Refletindo sobre Algumas Estratégias de Atuação. In: MUNANGA, Kabengele. (Org.). Superando o Racismo na Escola. 2. ed. rev. Brasília: SECAD, 2005. p.143-154.

Cultura Negra e Educação. Revista Brasileira de Educação. Maio/Jun./Jul./Ago., n. 23, 2003. Disponível em: 〈http://www.scielo.br/pdf/rbedu/n23/n23a05.pdf>. Acesso em: 〈20 de novembro de 2013〉.

Relações étnico-raciais, educação e descolonização dos currículos. Revista Currículo sem Fronteiras, v.12, n.1, pp. 98-109, Jan/Abr., $2012 . \quad$ Disponível em: <http://www.acaoeducativa.org.br/fdh/wpcontent/uploads/2012/11/currículo-e-relações- raciais-nilma-lino-gomes.pdf>. Acesso em: <22 de novembro de 2013>.

GOMES, N. L. Processos para a transversalidade emancipatória da África. Disponível em: 〈www.yotube.com.br〉. Acessado em: <20/05/2016, ás 12:30>.

JACCOUD, Luciana Barros. Racismo e República: o debate sobre o branqueamento e a discriminação racial no BrasilBrasília: IPEA, 2008. 
KI-ZERBO. J. Para onde vai a África? Codesria, Boletim, n. 3 e 4, 2007. Disponível em: 〈www.codesria.org>. Acessado em: <23/05/16, às 13.00>.

KOCHHANN, A.; MORAES. A. C. Aprendizagem significativa na perspectiva de David Ausubel. Anápolis: Editora da Universidade Estadual de Goiás, 2014.

LOPES, Alice Casimiro; MACEDO, Elizabeth. Teorias de Currículo. São Paulo: Cortez, 2011.

MINAYO, M. C. de S. (Org.). Pesquisa Social: Teoria, método e criatividade. Rio de Janeiro: Vozes, 1996.

; SANCHES, O. Quantitativo-Qualitativo: Oposição ou Complementaridade? Cad. Saúde Pública. Rio de Janeiro, 9 (3): 239-262 jul./set, 1993.

MOSER, V. A escola e os desafios contemporâneos. Rio de Janeiro: Civilização Brasileira, 2013.

MUNANGA. K. O Povo Negro. São Paulo: USP, 1996.

MUNANGA, Kabengele; GOMES, Nilma Rodrigues. O Negro no Brasil de Hoje. São Paulo: Global, 2006.

NASCIMENTO, A. do. O quilombismo. 2. ed. Brasília: Fundação Palmares, 2002.

NASCIMENTO, E. L. Afrocentricidade uma abordagem epistemológica inovadora. Disponível em: <www.universidadedasquebradas.pacc.ufrj.com.br>. Acessado em: <20/05/2016, às 14:30>.

O’DWYER. E. C. Quilombos Identidade Étnica e Territorialidade. Botafogo: FGV. 2002.

ROMÃO. J. E. Educação no século XXI saberes necessários segundo Freire e Morin. EccoS Revista Científica, vol. 2, núm. 2, dezembro, 2000. Disponível em: <http://www.redalyc.org/articulo.oa?id=71520203 >. Acessado em: $<20 / 06 / 2016$, às 9:30>.

SANTANA, C. E. C. Processos educativos na formação de uma identidade em comunidades remanescentes de quilombos: Um estudo sobre as comunidades de Barra / Bananal e Riacho das Pedras, no município de Rio de ContasBa. Disponível em: 〈wwww.cdi.uneb.br/pdfs $>$. Acessado em: $\langle 20 / 05 / 2016$, às 15:30>.

SANTOS, B. S. Para uma Sociologia das Ausências e uma Sociologia das Emergências. Coimbra: Revista Crítica de Ciências, Outubro, 2002.

SANTOS, B. S. S; MENESES, M. P. Epistemologias do Sul. Coimbra: Edições Coimbra, 2010.

SILVA, Adriana Maria Paulo. Reinventando um passado: diversidade ética e social dos alunos das aulas públicas de primeiras letras na corte, na primeira metade do século Xinxins: Cadernos PANESB, v. 8, dez. 2006.

SILVA. P. B. G; SILVÉRIO V. R. Educação e Ações Afirmativas: Entre a Injustiça Simbólica e a Injustiça Econômica. Brasília: Inep/MEC, novembro, 2003.

UNESCO. Educação Um Tesouro a Descobrir - Relatório da Unesco para a Comissão Internacional sobre Educação para o Século XXI. Brasília: Faber-Castell, 2010. 


\section{RESUMO}

Este artigo discute sobre a nova modalidade educacional brasileira a partir das perspectivas da educação quilombola. Subjaz por estruturação o pensamento do Prof. Boaventura de Sousa Santos ao sustentar o interacionismo epistemológico dos seres invisíveis, ausentes em muitas ações afirmativas. Ressalta-se que nessa tipologia de discurso, as lutas e avanços de todos os atores interacionistas foram expressões concretas e centrais que fizeram surgir "das terras de preto" uma sociedade que luta por melhores condições sociopolíticas há aproximadamente 500 anos. Por meio da educação, e de per si, também a familiar, transformam pessoas simples em 'cidadãs' e atores centrais deste enredo de luta, sofrimento e conquistas. Para tanto, esse processo histórico-social-cultural vem na contramão da colonialidade, em que foram extirpadas oportunidades de serem inseridos como seres humanos reconhecidos como povos nacionalmente brasileiros. Neste cenário, no qual as autoatribuições de trajetórias de vidas foram alimentadas pela resistência que, guardadas na memória, no linguajar, na produção do trabalho entre outros, produziu o nascer de uma aprendizagem significativa a "Afropedagogia dos Negros". No primeiro momento são praticadas nos domínios familiares, nos terreiros de matrizes africanas, nos quilombos, no jogar das capoeiras, entre outros. Esses enfoques fazem partes da temática dialogada pelo WhatsApp com os componentes do GEFOPI - Grupo de Estudos em Formação de Professores e Interdisciplinaridade, vinculado a UEG, Câmpus de São Luís de Montes Belos. Por conseguinte, faz-se necessário abrir as mentes para fundamentar-se, alimentar-se e informar-se nesta nova visão de mundo multicultural de educação que é um marco civilizatório da negritude, razão maior do seu pertencimento quilombola.

Palavras-chave: Educação. Movimento social. Lutas.

\section{DE LAS TIERRAS DE NEGRO EL AULA: MODALIDAD EDUCATIVA QUILOMBOLA, UNA ENSEÑANZA PARA TODOS}

\section{RESUMEN}

En este artículo, se discute sobre la nueva modalidad educativa brasileña, a partir de las perspectivas de la educación quilombola. En este sentido, Boaventura de Sousa Santos al sostener el interaccionismo epistemológico de los seres invisibles, ausentes en muchas acciones afirmativas. Se resalta que, en esta tipología de discurso, las luchas y avances de todos los actores interactivos fueron expresiones concretas y centrales que hicieron surgir "de las tierras de negro" una sociedad que lucha por mejores condiciones sociopolíticas desde hace aproximadamente 500 años. Por medio de la educación, y de por sí, también la familiar, transforman personas simples en 'ciudadanas' y actores centrales de esta trama de lucha, sufrimiento y conquistas. Para ello, ese proceso histórico-social-cultural viene en contra de la colonialidad, donde fueron extirpadas oportunidades de ser insertados como seres humanos que son y reconocidos como un pueblo nacionalmente brasileño. En este escenario, donde las auto atribuciones de trayectorias de vidas fueron alimentadas por la resistencia que, guardados en la memoria, en el lenguaje, en la producción del trabajo entre otros, produjo el nacer de un aprendizaje significativo a la "Afro pedagogía de los Negros". En el primer momento se practican en los dominios familiares, en los terreros de matrices africanas, en los quilombos, en el juego de las capoeiras, entre otros. Estos enfoques forman parte de la temática dialogada por el WhatsApp con los componentes del GEFOPI - Grupo de Estudios en Formación de Profesores e Interdisciplinariedad, vinculado a la UEG, Campus São Luís de Montes Belos. Por consiguiente, es necesario abrir las mentes para fundamentarse, alimentarse e informarse de esta nueva visión de mundo multicultural de la educación, que es un marco civilizatorio de la negritud, razón mayor de su pertenencia quilombola.

Palabras-clave: Educación. Movimiento social. Luchas. 


\section{FROM THE LANDS OF BLACK TO THE CLASSROOM: QUILOMBOLA EDUCATIONAL MODALITY, A TEACHING FOR ALL}

\section{ABSTRACT}

This article discusses the new Brazilian educational modality from the perspective of "quilombola" education. It underlies by structure the thought of professor Boaventura de Sousa Santos in sustaining the epistemological interactionism of the invisible beings, absent in many affirmative actions. It is noteworthy that in this typology of discourse, the struggles and advances of all interactionist actors were concrete and central expressions that brought "from the lands of black" a society that fought for better socio-political conditions about 500 years ago. Through education, and in a particular way, also the family, they transform simple people into 'citizens' and central actors of this plot of struggle, suffering and conquest. For this purpose, this historical-social-cultural process comes against coloniality, where opportunities to be inserted as human beings that are and recognized as nationally Brazilian people have been extirpated. In this scenario, where the self-attributions of life trajectories were fed by the resistance that, stored in memory, in language, in the production of work among others, produced the birth of a meaningful learning: the "Afropedagogy of the Blacks". In the first moment they are practiced in the familiar domains, in the terraces of African matrices, in the "quilombos", in the play of the "capoeiras", among others. These approaches are part of the WhatsApp dialogue with the components of GEFOPI - Group of Studies in Teacher Training and Interdisciplinarity, linked to UEG, Campus São Luís de Montes Belos. Therefore, it is necessary to open the minds to base themselves, to feed themselves and to be informed of this new vision of multicultural world of education that is a civilizatory mark of negritude, reason greater of its "quilombola" affiliation.

Keywords: Black lands. Education. Fights. 